\title{
Increasing Chlamydia Testing Rates via Targeted Outreach
}

\author{
Deyze Badarane, MD, MPH | Jordan Knox, MD | Ana Camacho, MA-C | Michael K. Magill, MD | \\ Sonja Van Hala, MD, MPH I Jessica L. Jones, MD, MSPH
}

PRiMER. 2019;3:17.

Published: 6/18/2019 | DOI: 10.22454/PRiMER.2019.669190

\section{Abstract}

Background and Objectives: Chlamydia trachomatis is the most prevalent bacterial sexually transmitted infection (STI) in the United States. Annual chlamydia screening of asymptomatic, sexually active women age 16 to 24 years and of older women who are at increased risk for infection is recommended. This study built on prior work in which our university-based family medicine clinic implemented quality improvement (QI) interventions in 2016 and 2017 to increase our chlamydia screening rate. Our primary aim in the current study was to increase the screening rate by $10 \%$. Our secondary aim was to determine the number of patient contacts that yielded maximum test rates.

Methods: For the most recent QI cycle, we conducted a prospective cohort study from December 2017 through March 2018. Using the FOCUS-PDSA model, a resident-led, interdisciplinary QI team developed the aims and implemented an intervention to streamline patient outreach. We also retrospectively analyzed data from the previous QI cycle to determine the number of tests obtained after each patient contact.

Results: Chlamydia testing increased from 54\% to 56.3\% between December 2017 and March 2018. The majority of tests were completed by four patient contacts; additional contacts yielded few additional tests.

Conclusions: Persistent outreach increases chlamydia screening rates. This QI project could be replicated in other clinical settings to improve the screening of chlamydia or other diseases.

\section{Introduction}

Chlamydia trachomatis is the most prevalent bacterial sexually transmitted infection (STI) in the United States. ${ }^{1}$ It causes pelvic inflammatory disease, ectopic pregnancy, and infertility. ${ }^{2,3}$ Annual chlamydia screening is recommended for asymptomatic, sexually active women age 16 to 24 years and older women at increased risk for infection. ${ }^{4}$ Despite the availability of noninvasive testing and effective treatment, rates of STI screening remain low. ${ }^{2}$

Our university-based family medicine clinic formed a quality improvement (QI) team to improve chlamydia screening rates through targeted outreach. Our primary aim was to increase the screening rate by $10 \%$ by March 2018 , starting from a baseline rate of $54 \%$ prior to December 2017. Our secondary aim was to evaluate trends in testing relative to the number of outreaches.

\section{Methods}

An interdisciplinary team of clinicians, medical assistants, front office staff, and public health providers met monthly 
throughout the year in order to improve chlamydia screening within our clinic. The team reviewed baseline chlamydia screening rates and developed an aim statement with a measurable outcome, defined goal, and time frame. We then developed a process chart of our clinic workflow to complete chlamydia screening (Figure 1). Next, we created a fishbone diagram that identified variation at each step of the process (Figure 2). The team proposed interventions using a nominal group technique. ${ }^{5}$ By consensus, we selected an intervention based on feasibility and impact.

Patients with overdue screening were not necessarily being seen in clinic. Thus, we developed a process to generate a list of patients from our electronic medical record who were overdue for chlamydia screening each month. We utilized this list for targeted outreach. Each month of the pilot intervention (December 2016 through May 2017), one medical assistant generated the list of patients overdue for screening, sent an informational letter (Figure 3) via secure patient portal, and ensured there was an order for the test. We tracked screening rates monthly, including months without outreach efforts, then repeated the outreach intervention the following year (December 2017 through March 2018).

For the second aim, we reviewed data from the 2016-2017 and 2017-2018 QI cycles to quantify the number of times patients were contacted, chlamydia screening rates, and the time of testing relative to outreaches. We calculated the number of patient outreaches prior to completed testing.

The University of Utah Institutional Review Board exempted this project (IRB \#00116258). ${ }^{6}$

\section{Results}

The number of eligible patients meeting inclusion criteria changed each month. Therefore, the number of patients contacted with each attempt varied. The average number of eligible patients per month during the 2016-2017 and 2017-2018 QI cycles was 60.6 women (range: 49-75) and 60.2 (range: 51-68), respectively. The average age of eligible women during both cycles was 22 years.

During the first cycle, annual chlamydia testing increased from 58.4\% in December 2016 to $66.4 \%$ by May 2017. Between cycles (May-November 2017), screening decreased $12.4 \%$ to a rate of $54.0 \%$. After the second cycle, the testing rates reached $56.3 \%$ by March 2018, a $2.3 \%$ increase (Figure 4).

For the secondary analysis, 604 patient records were reviewed: 303 from the 2016-2017 cycle, and 301 from the 2017-2018 cycle. During the 2016-2017 cycle, 26 patients obtained chlamydia testing: 14, 7, 4, 1, and 0 respectively after the first five attempts (Table 1). The number of completed tests did not increase further after four contacts. One hundred ninety-one electronic outreach messages were sent. Of these, $150(78.5 \%)$ patients read the message; $41(21.5 \%)$ did not. Percentages of patients reading the messages were $33.5 \%, 31.4 \%, 10.5 \%$, and $3.1 \%$ after the first through fourth attempts, respectively (Table 2 ).

During the 2017-2018 cycle, 19 patients completed the screening: 9, 7, 2, 0, 1, and 0 after the first five outreach attempts (Table 1). One hundred fifty-eight electronic messages were sent. Of these, $110(69.6 \%)$ patients read the message; 48 (30.4\%) did not. Percentage of patients reading the messages were $6.3 \%, 29.1 \%, 15.8 \%, 8.9 \%, 5.7 \%$, and $3.8 \%$ after the first through sixth outreach attempts, respectively (Table 2).

\section{Discussion}

We did not achieve our primary aim to increase the proportion of chlamydia screening by $10 \%$. However, the chlamydia testing rates improved and exceeded the national and local rates of $49.8 \%$ and $32.8 \%$, respectively. ${ }^{7}$ The testing rates declined between the two QI cycles when the outreach intervention was not being applied. The majority of patients read the electronic messages suggesting that this is a useful tool to communicate with the target audience. While most testing was completed within one or two reminders, additional reminders (up to five outreaches) achieved an increased total number of completed tests. This was accomplished without a significant increase in staff workload, as we had simplified our outreach. 
Staff time is a barrier to patient outreach. We streamlined the outreach process to less than 5 minutes: designated staff generates the list of patients overdue for testing, and sends a message to each individual's patient portal encouraging them to be screened. Patient orders had been a barrier, requiring staff to ensure orders were available for eligible patients. This barrier was removed when, subsequent to the last QI cycle (2017-2018), team members developed a protocol for standing chlamydia screening orders for patients meeting the United States Preventive Services Task Force criteria across the university-based health care system.

This QI project had several limitations, including the single clinic setting, small sample size, inability to capture outside testing, and a moving target of the eligible population. Different patients qualified for or fell out of the target pool daily, based on birth date and whether their annual testing was due, yet we collected data and performed outreach only monthly. Despite these limitations, this project demonstrated increased testing during each intervention period. Future QI endeavors should augment efforts to improve the sustainability and efficacy of outreach.

The interventions successfully implemented in our university-based family medicine clinic demonstrated clinical improvement in chlamydia screening outreach for young adult women within the primary care settings. The QI project could be replicated in other clinical settings to reduce the burden of Chlamydia trachomatis infection or to improve the screening of other STDs.

\section{Tables and Figures}


Figure 1: Process Diagram, Cycle 1 (2016-2017)

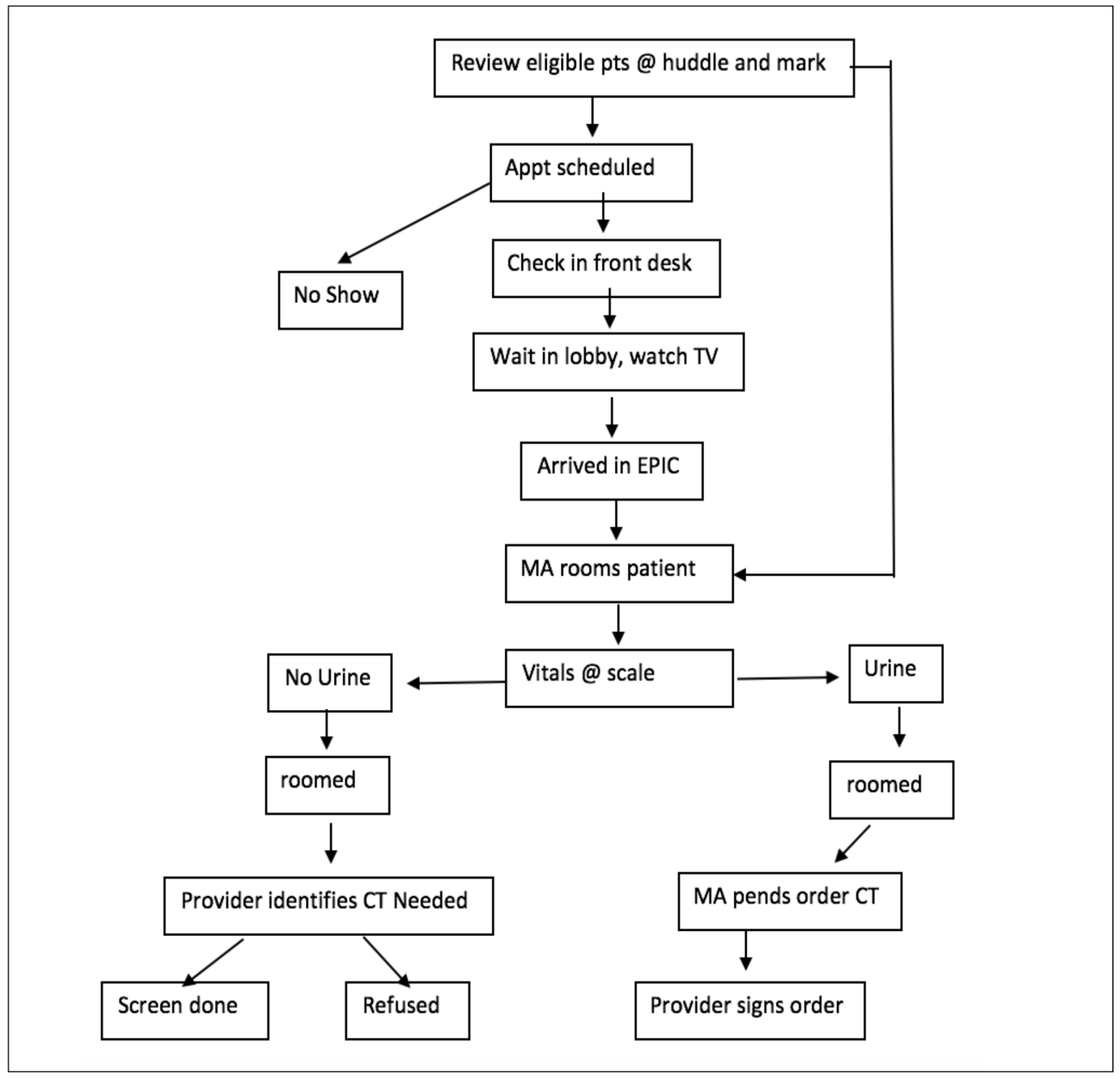


Figure 2: Fishbone Diagram, Cycle 1 (2016-2017)

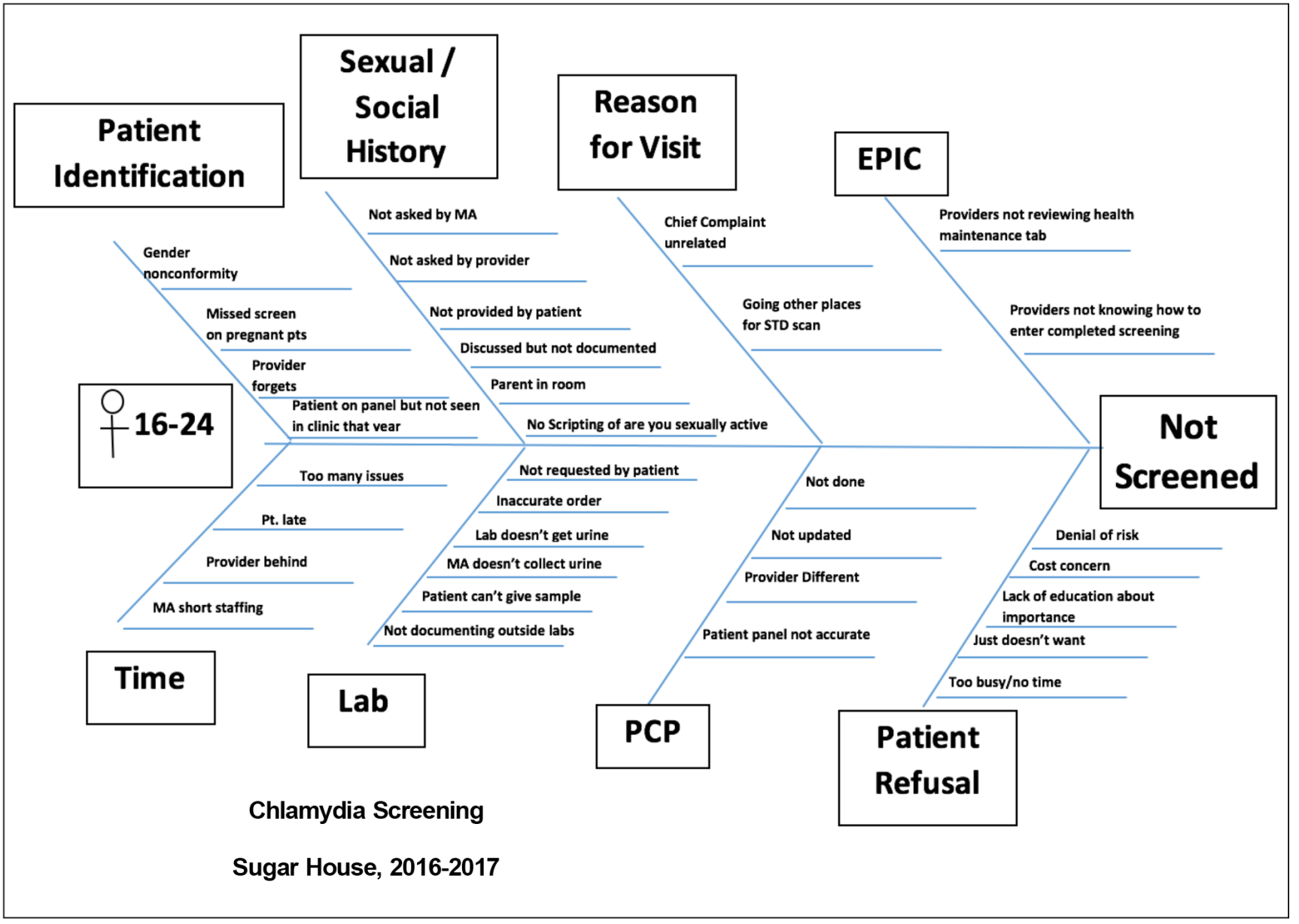


Figure 3: Informational Letter

(ELECTRONIC HEALTH RECORD MESSAGE VIA ENCRYPTED PATIENT PORTAL)

GREETINGS!

ACCORDING TO OUR RECORDS, YOU MAY BE DUE FOR A YEARLY CHLAMYDIA

SCREENING. CHLAMYDIA IS A SEXUALLY TRANSMITTED INFECTION THAT CAN CAUSE

INFERTILITY, PELVIC INFECTION, AND PELVIC PAIN. MANY WOMEN HAVE

CHLAMYDIA AND DO NOT KNOW IT. WE SCREEN FOR CHLAMYDIA WITH A SIMPLE

URINE TEST AND IT IS EASILY TREATED. PLEASE CONTACT THE CLINIC FOR A LAB

APPOINTMENT.

IF YOU HAVE FURTHER QUESTIONS ABOUT CHLAMYDIA PLEASE SCHEDULE AN

APPOINTMENT WITH YOUR PROVIDER.

CHLAMYDIA SCREENING IS RECOMMENDED EVERY YEAR FOR SEXUALLY ACTIVE

FEMALES AGES 16-24.

FOR MORE INFO, PLEASE VISIT CDC WEBSITE:

HTTP://WWW.CDC.GOV/STD/CHLAMYDIA/DEFAULT.HTM

BEST REGARDS,

YOUR HEALTH CARE PROVIDERS AT SUGAR HOUSE FAMILY HEALTH CENTER

Figure 4: Run Chart of Eligible Patients Undergoing Chlamydia Screening by Month

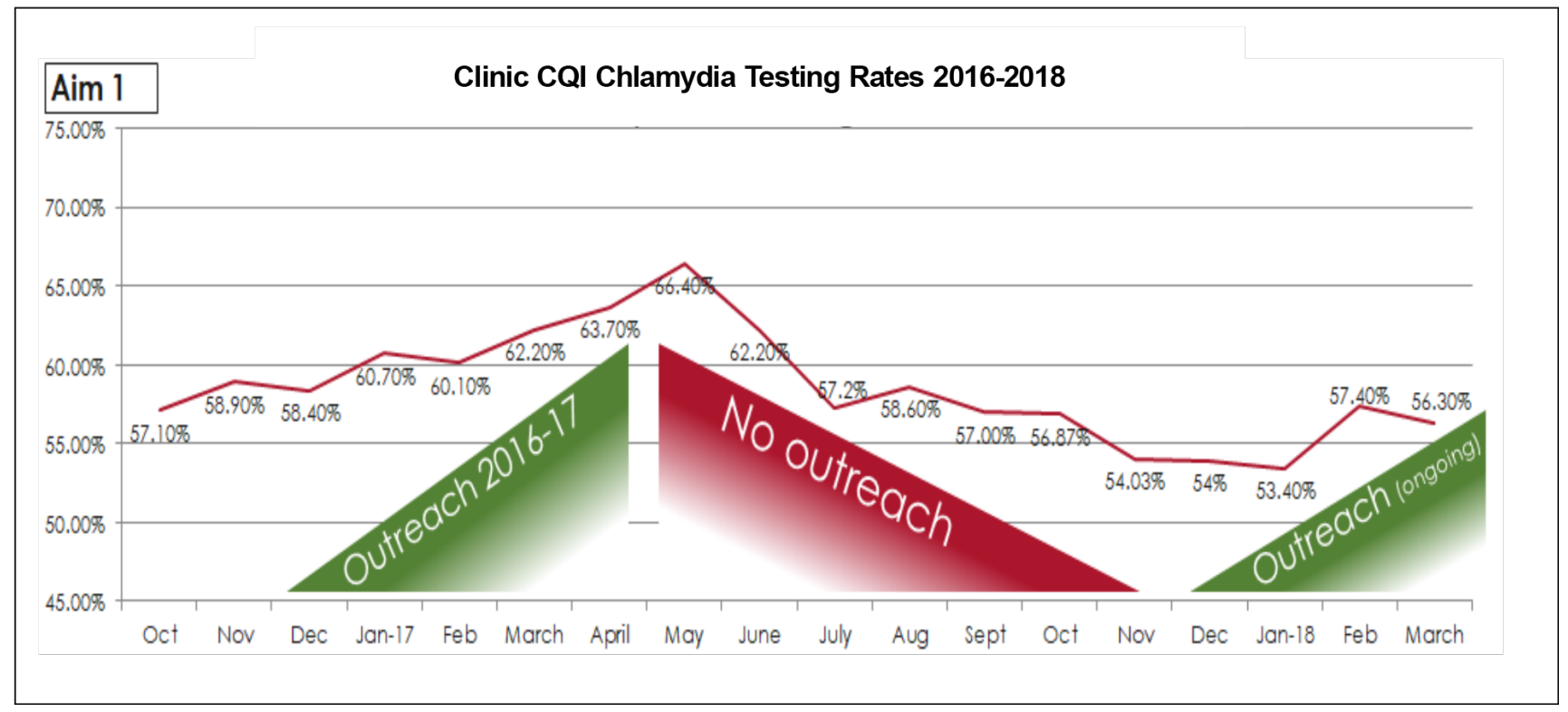


Table 1: Impact of Patient Outreaches (Number of Monthly Outreaches Until Testing Completed)

\begin{tabular}{|c|c|c|c|}
\hline $\begin{array}{l}\text { Outreach } \\
\text { Attempts }\end{array}$ & $\begin{array}{l}\text { Total Number of Monthly } \\
\text { Outreaches (Letter or } \\
\text { Electronic Message) }\end{array}$ & $\begin{array}{l}\text { Number of } \\
\text { Completed } \\
\text { Chlamydia Tests }\end{array}$ & $\begin{array}{c}\text { Percent of Target Population } \\
\text { That Completed Chlamydia } \\
\text { Test/Monthly Outreach }\end{array}$ \\
\hline \multicolumn{4}{|c|}{ 2016-2017 } \\
\hline First & 141 & 14 & 9.90 \\
\hline Second & 100 & 7 & 7.00 \\
\hline Third & 39 & 4 & 10.30 \\
\hline Fourth & 19 & 1 & 5.30 \\
\hline Fifth & 4 & 0 & 0.00 \\
\hline Total & 303 & 26 & 32.40 \\
\hline \multicolumn{4}{|c|}{ 2017-2018 } \\
\hline First & 88 & 9 & 10.20 \\
\hline Second & 96 & 7 & 7.30 \\
\hline Third & 54 & 2 & 3.70 \\
\hline Fourth & 33 & 0 & 0.00 \\
\hline Fifth & 19 & 1 & 5.30 \\
\hline Sixth & 11 & 0 & 0.00 \\
\hline Total & 301 & 19 & 6.30 \\
\hline
\end{tabular}


Table 2: Number of Patients Who Read or Did Not Read Electronic Message by Number of Outreach Attempts: Cycle 1 (2016-2017) and Cycle 2 (2017-2018)

\begin{tabular}{|c|c|c|c|c|c|c|c|}
\hline \multicolumn{8}{|c|}{ Cycle 1-Read } \\
\hline & January & February & March & April & Total & \multicolumn{2}{|c|}{ Total $(\%)$} \\
\hline First attempt & 26 & 18 & 12 & 8 & 64 & \multicolumn{2}{|c|}{33.5} \\
\hline Second attempt & 21 & 18 & 10 & 11 & 60 & \multicolumn{2}{|c|}{31.4} \\
\hline Third attempt & & 4 & 8 & 8 & 20 & \multicolumn{2}{|c|}{10.5} \\
\hline Fourth attempt & & & 2 & 4 & 6 & \multicolumn{2}{|c|}{3.1} \\
\hline Total & 47 & 40 & 32 & 31 & 150 & & \\
\hline \multicolumn{8}{|c|}{ Cycle 1-Not Read } \\
\hline First attempt & 6 & & 2 & 4 & 12 & \multicolumn{2}{|c|}{6.3} \\
\hline Second attempt & 7 & 11 & 6 & 3 & 27 & \multicolumn{2}{|c|}{14.1} \\
\hline Third attempt & & 1 & & 1 & 2 & \multicolumn{2}{|c|}{1.0} \\
\hline Total & 13 & 12 & 8 & 8 & 41 & & \\
\hline \multicolumn{5}{|c|}{ Total Read + Not Read } & 191 & & \\
\hline \multicolumn{8}{|c|}{ Cycle 2-Read } \\
\hline & November & December & January & February & March & Total & $\begin{array}{c}\text { Total } \\
(\%)\end{array}$ \\
\hline First attempt & 4 & & & 4 & 2 & 10 & 6.3 \\
\hline Second attempt & 19 & 8 & 10 & 6 & 3 & 46 & 29.1 \\
\hline Third attempt & 2 & 5 & 8 & 7 & 3 & 25 & 15.8 \\
\hline Fourth attempt & 3 & 2 & 3 & 2 & 4 & 14 & 8.9 \\
\hline Fifth attempt & 1 & 2 & 1 & 3 & 2 & 9 & 5.7 \\
\hline Sixth attempt & 1 & 1 & 1 & 2 & 1 & 6 & 3.8 \\
\hline Total & 30 & 18 & 23 & 24 & 15 & 110 & \\
\hline \multicolumn{8}{|c|}{ Cycle 2-Not Read } \\
\hline First attempt & & & & & & 0 & 0.0 \\
\hline Second attempt & 8 & 2 & 7 & 6 & & 23 & 14.6 \\
\hline Third attempt & 1 & 2 & 1 & 6 & 4 & 14 & 8.9 \\
\hline Fourth attempt & & & 2 & 2 & 2 & 6 & 3.8 \\
\hline Fifth attempt & 1 & 1 & & & 1 & 3 & 1.9 \\
\hline Sixth attempt & & & 1 & & 1 & 2 & 1.3 \\
\hline Total & 10 & 5 & 11 & 14 & 8 & 48 & \\
\hline \multicolumn{6}{|c|}{ Total Read + Not Read } & 158 & \\
\hline
\end{tabular}

\section{Acknowledgments}

The authors thank the following individuals for their support:

Julia Kammel, MD; Melissa See, MD, MPA; Lindsey Yanke, MD; Malea Satterwhite, PA-C; Sam Osimitz, A-EMT; Jessica Mella, MA-C; José Rodríguez, MD, FAAFP.

Financial Support: Financial support for this study was provided by Gross Endowment, University of Utah Department of Family and Preventive Medicine.

\section{Presentations:}

1. Knox J, et al. Outreach to Increase Chlamydia Testing Rates: Is There a Breakpoint for Optimal Number of Patient Contacts? Ogden Surgical-Medical Society Meeting Doctorate Section Poster Presentation, Ogden, UT, May 16, 2018. 
2. Knox, J, et al. Outreach to Increase Chlamydia Testing Rates: Is There a Breakpoint for Optimal Number of Patient Contacts? Annual 2018 Fellows, Residents, or Students Research Works-in-Progress Poster. $51^{\text {st }}$ STFM Annual Spring Conference. Washington, DC, May 8, 2017.

3. Knox J, et al. Increasing Chlamydia Testing Rates via Targeted Outreach. UHealth Evidence-Based Practice Poster Fair, Salt Lake City, UT, April 25, 2018.

4. Knox J, et al. Increasing Chlamydia Testing Rates via Targeted Outreach. Utah Academy of Family Physicians CME-N-Ski Conference, Park City, UT, February 23, 2018.

\section{Corresponding Author}

Jessica L. Jones, MD, MSPH

375 Chipeta Way Ste A, SLC, UT 84108. 310-592-1024. Fax: 801-587-3353.

jessica.L.Jones@utah.edu

\section{Author Affiliations}

Deyze Badarane, MD, MPH - Division of Public Health, University of Utah School of Medicine, Salt Lake City, UT Jordan Knox, MD - Department of Family and Preventive Medicine, University of Utah School of Medicine, Salt Lake City, UT

Ana Camacho, MA-C - Sugarhouse Family Health Center, University of Utah Health, Salt Lake City, UT

Michael K. Magill, MD - Department of Family and Preventive Medicine, University of Utah School of Medicine, Salt Lake City, UT

Sonja Van Hala, MD, MPH - Department of Family and Preventive Medicine, University of Utah School of Medicine, Salt Lake City, UT

Jessica L. Jones, MD, MSPH - Department of Family and Preventive Medicine, University of Utah School of Medicine, Salt Lake City, UT

\section{References}

1. Rorrone E, Papp J, Weinstock $\mathrm{H}$. Prevalence of chlamydia trachomatis genital infection among persons aged 14-39 years - United States, 2007-2012. CDC MMWR. 2014;63(38):834-838. https://www.cdc.gov /mmwr/preview/mmwrhtml/mm6338a3.htm. Accessed June 10, 2019.

2. Phillipson L, Gordon R, Telenta J, Magee C, Janssen M. A review of current practices to increase Chlamydia screening in the community-a consumer-centred social marketing perspective. Health Expect. 2016;19(1):5-25. https://doi.org/10.1111/hex.12337

3. Hahn AW, Geisler WM. Chlamydia. National STI Curriculum. https://www.std.uw.edu/go/pathogenbased/chlamydia/core-concept/all. Updated October 26, 2018. Accssed June 10, 2019.

4. US Preventive Services Task Force. Final Recommendation Statement: Chlamydia and Gonorrhea: Screening. https://www.uspreventiveservicestaskforce.org/Page/Document/RecommendationStatementFinal /chlamydia-and-gonorrhea-screening. Accessed June 10, 2019.

5. Fink A, Kosecoff J, Chassin M, Brook RH. Consensus methods: characteristics and guidelines for use. Am J Public Health. 1984;74(9):979-983. https://doi.org/10.2105/AJPH.74.9.979

6. University of Utah Institutional Review Board. Non-Human Subject Research. https://irb.utah.edu/guidelines /human-subject-research.php. Accessed June 10, 2019.

7. Centers for Disease Control and Prevention. 2016 Sexually Transmitted Diseases Surveillance. https://www.cdc.gov/std/stats16/CDC_2016_STDS_Report-for508WebSep21_2017_1644.pdf. Published 2017. Accessed June 10, 2019.

Copyright $@ 2019$ by the Society of Teachers of Family Medicine 